\title{
Epidemiological Study of Technopaties in Amateur Basketball Players
}

\author{
Daffé $M,{ }^{1,2}$ Kivandat DN, ' Dembélé $B,{ }^{2}$ Sarr L,' Diouf AB, ' Sané AD, ${ }^{2}$ Diémé CB' \\ 'Centre Hopitalier Universtaire Aristide Le Dantec, Dakar \\ ${ }^{2}$ Centre Hospitalier National Dalal Jamm, Guédiawaye, Dakar
}

Correspondence: Daffe Mohamed, Centre Hopitalier Universtaire Aristide Le Dantec, Dakar, Tel 00(22I)775357454,

Email mohameddaffe78@yahoo.fr

Received: August 10,20I8 | Published: September 28, 2018

Copyright@ 2018 Daffé et al. This is an open access article distributed under the terms of the Creative Commons Attribution License, which permits unrestricted use, distribution, and reproduction in any medium, provided the original author and source are credited.

\begin{abstract}
Introduction

Basketball is a complete sport for a broad audience that can find all the satisfactions associated with physical exercise. His practice is constantly increasing with the development of a game more and more physical, contributing to the increase of the frequency of the traumatisms. The main cause of injury is the contact with the opponent, but overload pathologies are not negligible. Our study aimed to determine the epidemiological aspects of the technopathies frequently encountered in basketball players.
\end{abstract}

\section{Materials and methods}

We collected 20 cases (19 men). The average duration of basketball practice (to date) was 23.35 years with extremes of 10 and 28 years. Those amateur basketball players played 3 times a week during at least 5 years. Professional and casual (who played when they want, can stay months without play) basketball players weren't included. The selection of patients was thorough, a data collection sheet had been duly completed.

\section{Introduction}

Basketball is a complete sport for a broad audience that can find all the satisfactions associated with physical exercise. It is one of the collective sports modifying its regulations with the most regularity. ${ }^{1}$

The solicitation of the lower limbs is made of specific strong supports, blocking, changes of direction, acceleration, deceleration and finally jumps. The upper limbs contribute mainly to the movements of the ball and the precision of the shots but they undergo significant constraints of contact with the opponents both in defense and attack. This whole context makes the basketball player a potential target of musculoskeletal trauma.

Technopathy represents all traumatic injuries (acute or wear) specific to the practice of a given sport.

The purpose of our study was to take stock of the epidemiological aspects of lesions of technopathies frequently encountered in amateur basketball players (commonly known as "playgrounders").

\section{Materials and methods}

\section{Population}

It was a retrospective study conducted at the Olympic Club in Senegal for one month (July 2016) that evaluated a group of basketball players

\section{Results}

There were 25 specific traumatic injuries and 8 overload injuries. The trauma of the lower limbs represented $72 \%$. The muscular contusions had not been taken into account. Ankle sprain and ACL rupture were the most common lesions. Medical imaging was performed in all patients. There were 7 surgical patients. Accidents involving contact with the adversary accounted for $44 \%$ of the trauma.

\section{Conclusion}

Basket-ball is constantly increasing with the development of a game more and more physical, contributing to the increase of the frequency of the traumatisms. Extremely stressed, the osteoarticular and musculotendinous systems of the upper and lower limbs are permanently exposed to risks of sprains, fractures and various trauma.

Keywords: basketball-technopathies-overloads injuries.

Selection criteria: passionate basketball players who are physically at least 18 years old and who have been playing basketball for more than five years (amateur or semi-professional), who are active and who, after the practice of basketball, have suffered an injury of the musculoskeletal system supported in a hospital environment. Those amateur basketball players played at least 3 times a week. The semiprofessional trained at least 4 times a week and played competition matches during week end.

The criteria for non-inclusion were: Casual basketball players (basketball players who play accidentally a week, month or year); professional basketball players.

The data was collected from a survey card based on the criteria of our study for a group of amateur basketball players.

There were 20 players (19 men and one woman) whose average age was 37.5 years with extremes of 30 and 45 years. Their average weight was $89.15 \mathrm{~kg}$ (72 and $110 \mathrm{~kg}$ extreme) for an average height of $1.90 \mathrm{~m}$ (extremes of $1 \mathrm{~m} 70$ and $2 \mathrm{~m} 05$ ). The average frequency of weekly basketball sessions for all our players was three (3). Apart from basketball, the other sports practiced were: jogging $(\mathrm{n}=18)$, bodybuilding $(\mathrm{n}=15)$, swimming $(\mathrm{n}=10)$, football $(\mathrm{n}=15)$ and martial arts $(n=2)$. The players who played in competition were 16 in number.
Submit your Article | www.ologypress.com/submit-article OP Ology $f$ in $y$ ritios
Citation: Daffé M, Kivandat DN, Dembélé B, et al. Epidemiological Study of Technopaties in Amateur Basketball Players. Orthopedics Traumatology Spor Med Int J. (20I8); I: I 7-20. DOI: I0.3088I/otsmij.00005 


\section{Methodology}

For each player included in the study, a data collection sheet was duly completed by the same investigator.

In addition to the identification of the patient, epidemiological data of the lesional aspects were noted on the individual record of collection.

\section{Results}

The mean follow-up was 54.85 months with extremes of 24 and 84 months.

We found 25 acute traumatic injuries that occurred during the practice of basketball for 8 wear injuries.

Lesions of the musculoskeletal system were distributed as follows:

\section{For acute post-traumatic injuries}

To the upper limbs (Table I)

Table I Distribution of upper limb lesions

\begin{tabular}{ll}
\hline Nature of lesions & Number \\
\hline Postero lateral elbow discolation & $\mathrm{I}$ \\
Fracture 2 bones of forearm & $\mathrm{I}$ \\
Maillet finger & 4 \\
Wrist sprained collateral ligament & $\mathrm{I}$ \\
Total & $\mathbf{7}$ \\
\hline
\end{tabular}

For acute post-traumatic injuries:

To the upper limbs (Table I)

To the lower limbs (Table II)

\section{For chronic or wear injuries (Table III)}

Two players in the study presented 2 chronic lesions of the musculoskeletal system (lumbar disc herniation associated with tendinopathy of the patellar ligament for one and rotator cuff for the other).

Table 2 Distribution of lesions in the lower limb

\begin{tabular}{ll}
\hline Nature of the lesions & Number \\
\hline ACL knee rupture & 05 \\
Patellar ligament rupture & 01 \\
Meniscal lesion & 03 \\
LCl knee benign sprain & 01 \\
Leg fracture (tibia) & 01 \\
Ankle sprain & 05 \\
Internal malleolar isolated & 01 \\
fracture & 01 \\
\hline Achilles tendon rupture & $\mathbf{1 8}$ \\
\hline Total & \\
\hline
\end{tabular}

Table 3 Distribution of chronic lesions

\begin{tabular}{ll}
\hline Nature of lesions & Number \\
\hline Lumbar disc herniation (LDH) & 3 \\
Tendinopathy of rotators cuff & $\mathrm{I}$ \\
Chronic patellar ligamentous & 2 \\
tendinopathy Haglund disease & $\mathrm{I}$ \\
Plantar fasciitis & $\mathrm{I}$ \\
\hline Total & $\mathbf{8}$ \\
\hline
\end{tabular}

\section{Discussion}

\section{Acute lesions}

Traumatic injuries to the upper limbs accounted for $28 \%$ of all specific traumatic injuries.

The upper limbs contribute mainly to the movements of the ball and the precision of the shots but they also undergo significant constraints against the opponents both in attack and in defense.

The finger-mallet fingers accounted for $16 \%$ of the specific traumatic injuries in the series. According to several studies, ${ }^{2-4}$ traumatic injuries of the fingers are recurrent during the practice of Basketball. For Ito et al, ${ }^{5}$ traumatic finger lesions among basketball players accounted for $7.4 \%$ (lower than our series).

Wrist sprain accounted for $14.28 \%$ of trauma. According to authors Deitch $\mathrm{JR}^{4}$ and Dick $\mathrm{R},{ }^{6}$ sprains are the most common wrist pathologies with $1.3 \%$ in National Basketball Association (NBA), $1 \%$ in Women's National Basketball Association (WNBA) and 1, 6\% in the National Collegiate Athletic Association (NCAA) male.

Fracture of both forearm bones and posterolateral elbow dislocation accounted for the remainder of the specific lesions. No literature data on his specific basketball injuries were found.

Lower limb trauma accounted for $72 \%(n=18)$ of all specific traumatic injuries.

According to two studies ${ }^{2,6}$ involving 16 years of observation (19882004 ) in the NCAA, ankle injuries remain the most common lesions (25.3\% of the most serious injuries occurring during contact with another player). The lower part of the body is the most frequently reached area, both during matches $(26.2 \%$ of men and $24.6 \%$ of women), as during training ( $26.8 \%$ of basketball players and $23.6 \%$ basketball players). Knee problems (7.4\% of basketball players and $15.3 \%$ of basketball players) are recurrent in NCAA.

Repetitive jumps interspersed with racing and change of direction are responsible for a higher number of injuries to the lower limbs $(62.4 \%)$ compared to the upper limbs $(37.6 \%)^{7}$

Ankle sprains and knee injuries were the most common in our study. They accounted for $27.7 \%$ and $55.5 \%$ respectively. Indeed, ankle injuries are often benign and allow the basketball player to continue his practice despite a physical limitation. Ankle injury is the leading cause of injury according to the International Amateur Basketball Federation (FIBA) with $92.8 \%$ of lesions affecting the lateral collateral ligament (most vulnerable area). ${ }^{8}$ In the NBA and Pro A (first division men's championship) in France, we find respectively the same lesion in the ankle with $17.3 \%$ and $25 \%{ }^{4,9}$ The reception during a jump is the main mechanism of injury, but to this, are added the abrupt changes of direction. It should be noted that $66 \%$ of athletes who suffered ankle injuries had a history of sprain and that the follow-up of these longterm injuries showed a recurrence rate of 40 to $50 \%{ }^{5}$

Ito et al. ${ }^{5}$ note that in Japan, ankle sprain is more common among female basketball players $(64.4 \%)$ than men $(58 \%)$.

Historically, ankle sprains and basketball are closely linked. All studies identified ankle sprains as one of the major injuries found in this sport ${ }^{2,7,10,11}$ and at any level of play. ${ }^{12}$ Our study confirms this trend. The occurrence of an ankle sprain leads to an increase in ligament laxity which may be a predictor of later instability. ${ }^{13}$

However, severe injuries to the knee often require the immediate end of the practice minutes after the trauma. Breaks in the ACL account for $27.7 \%$ of traumatic injuries to the lower limb. Our results are 
significantly superior to those of Hickey et al. ${ }^{14}$ which was $1.8 \%$. For Parkkari et al. ${ }^{15}$ the relative risk of ACL rupture was twice as high for girls with sports activities greater than four times a week compared to boys. There was no difference for a sports activity less than three times a week. The rupture of the ACL was found in the only girl of our series. For Prodromos et al., ${ }^{16}$ basketball is one of the most risky sports for girls. For meniscal lesions, there were two internal meniscal lesions associated with ACL rupture and one external meniscal lesion on stable knee. In the literature, these lesions concern more the medial meniscus than lateral and are rarely isolated at the sportsman. ${ }^{17}$ Before 30 years of age, they are often associated with central pivot involvement, and are then of poorer prognosis, ${ }^{18}$ and after 40 years they most often mask degenerative bone lesions.

The rupture of Achilles tendon when to it, can occur at the high level and occasional athlete. ${ }^{19}$ The essential factor of rupture is mechanical. A case was found in our series. However, O. Jarde in his study found 02 cases of traumatic Achilles tendon rupture in basketball. ${ }^{19}$

Fractures accounted for $11.11 \%$ of traumatic lower limb injuries. No data were found in the literature on the specificity of fractures in the basketball player.

\section{Chronic lesions or wear injuries}

Daily sports practice exposes to undetected microtrauma that can be revealed over time.

In the upper limb, only one case of tendinopathy of the rotator cuff was found in our study. Joint and tendon hypersollicitation, poor gestures and age can be considered as risk factors for microtrauma. The average age in our study was 37.5 years old. Basketball is a rather demanding sport in which several movements of the musculoskeletal system are solicited; the intensity of the matches both in competition (high level) and amateur level requires a certain physical condition. Some of these qualities diminish over time.

Three cases of lumbar disc herniations have been found in our series. All sports activities can cause lumbar disc herniation. In French Pro A, low back pain is the fourth leading cause of stopping sports after ankle sprain, muscle injuries and all technopathies. In the NBA, this is the third pathology in terms of frequency with $5.8 \%$. In WNBA this incidence is 3.6\%. ${ }^{4}$ The repetition of "dunk" is incriminated. ${ }^{9}$

A study of French professional players shows that the main back injury is paralumbar muscle contracture $(14.3 \%){ }^{3}$

All sports that cause significant axial overload (weightlifting, downhill skiing, etc.) associated with rotation or lateral inclination (basketball, handball, volleyball, etc.) can be the cause of disc pathology by repeated microtrauma on the intervertebral disc.

The general biomechanics of sport explains these microtrauma, but for each sport it is necessary to distinguish the various disciplines, or even each position within a team. ${ }^{20}$ It will be necessary to take into account extrasportive, professional or parallel sports activities.

Tendinopathy of the patellar ligament or "jumper knee" is a very common pathology in this sport that requires repeated jumps. In our study it accounted for $50 \%$ of overuse injuries in the lower limbs. Its prevalence varies according to the level practiced. According to Van der Worp, ${ }^{21}$ in basketball it is respectively $32 \%$ (high level basketball players) and $12 \%$ (amateurs). A study conducted in Norway $^{22}$ on a population of high-level athletes, in 9 different sports disciplines, found a general prevalence (signs present in imaging) of $14.2 \%$ patellar ligament tendinopathy. For athletes who developed the symptoms, it was higher among volleyball players (44.6\%) and basketball players $(31.9 \%)$. No difference between men and women was found. Male athletes have a prevalence twice as high as female athletes. ${ }^{22}$ However, this pathology also affects children as in the case of basketball where a prevalence of $7 \%$ could be reported in a population according to Rudovsky. ${ }^{23}$

The etiologies appear to be multiple: ${ }^{4}$ overweight, length discrepancy of the lower limbs, hollow feet, stiffness of the hamstrings, quadriceps muscle strength and vertical impulse. Extrinsic factors were also mentioned: the volume and the training load, the type of terrain or the unsuitable material. ${ }^{25}$ The patient in the study who presented this pathology was 38 years old for a height of $2 \mathrm{~m} 10$ and having played professionally for 15 years. He had a flat foot. For Guincestre et al. tendinopathies of the extensor apparatus would be less frequent on synthetic soil which more or less dampens the fall or the reception of jumps.

In addition, the occurrence of a first episode of injury increases the risk of new outbreaks. ${ }^{26}$ Due to its often chronic installation, patellar technopathy is sometimes very long to treat, having a direct impact on the sports performance of the athlete. ${ }^{27}$ At the end of their careers, $53 \%$ of athletes who have suffered from PT who admit to having ended their career early because of the latter. ${ }^{28}$

Plantar fasciitis accounted for $25 \%$ of the lower limb overload lesions in the study. The prevalence among athletes varies between 10 and $20 \% .{ }^{29}$ This pathology is observed both in athletes and non-athletes. It occurs most of the time around the age of 40 even if all age groups are interested. No difference in frequency has been demonstrated for sex. ${ }^{30}$ If the exact etiology remains unknown, it remains close to that of tendinopathies. In athletes, inappropriate footwear or hard ground are contributing factors..$^{31}$ On the other hand, the anatomical morphology of the foot can also have an influence such as the flat valgus foot with a calcaneal horizentalisation, an eversion of the subtalar articulation too marked, the hollow foot exerting a tension on the plantar fascia or still hyperpronation of the foot in dynamics. ${ }^{32}$ Concerning the calcaneal spine, confusion exists as to whether it is the cause or the consequence. Some argue that the calcaneal spine is an adaptation to vertical compression at the level of calcaneal anthesis. ${ }^{33}$

For the patient with Haglund's disease, the clinical examination had found a foot with a normal architecture. It is a pathology generally associated with intense physical activities such as running or jumping. It is most often found among athletes practicing medium and long distance races (prevalence of 7 to $9 \%$ for high level), orienteering, athletics, tennis, basketball and ${ }^{34,35}$ This patient reported regular middistance racing sessions.

\section{Conclusion}

Basket-ball is constantly increasing with the development of a game more and more physical, contributing to the increase of the frequency of the traumatisms. Extremely stressed, the osteoarticular and musculotendinous systems of the upper and lower limbs are permanently exposed to risks of sprains, fractures and various trauma.

\section{Disclosure}

The authors report no conflict of interest concerning the materials or methods used in this study or the findings specified in this paper.

\section{References}

1. Bouvard M, Cormery B, Susuki M. La traumatologie du basketteur de haut niveau. Dix ans d'expérience dans un club européen. J Traumatol Sport. 2006;23(1):36-37. 
2. Agel J, Olson DE, Dick R, Arendt EA, Marshall SW, Sikka RS Descriptive epidemiology of collegiate women's basketball injuries: National Collegiate Athletic Association Injury Surveillance System, 1988-1989 through 2003-2004. J Athl Train. 2007;42(2):202.

3. Buffet M, Morel N, Navacchia M, Voyez J, Vella-Boucaud J, Edouard P Blessures chez des joueuses de basketball féminin de haut niveau durant une saison. Sci Sports. 2015;30(3):134-146.

4. Deitch JR, Starkey C, Walters SL, Moseley JB. Injury risk in professiona basketball players: a comparison of Women's National Basketball Association and National Basketball Association athletes. Am J Sports Med. 2006;34(7):1077-1083.

5. Ito E, Iwamoto J, Azuma K, Matsumoto H. Sex-specific differences in injury types among basketball players. Open Access $J$ Sports Med. 2015;6:1.

6. Dick R, Hertel J, Agel J, Grossman J, Marshall SW. Descriptive epidemiology of collegiate men's basketball injuries: National Collegiate Athletic Association Injury Surveillance System, 1988-1989 through 2003-2004. J Athl Train. 2007;42(2):194.

7. Drakos MC, Domb B, Starkey C, Callahan L, Allen AA. Injury in the National Basketball Association: a 17-year overview. Sports Health 2010;2(4):284-290.

8. International Basketball Federation (FIBA) - FIBA.basketball. http:// www.fiba.basketball/. Accessed September 11, 2018.

9. Huguet J, Bégué J. La pathologie du basketball. Rhumatologie 1998;50(4-5):152-156.

10. Starkey C. Injuries and illnesses in the National Basketball Association: a 10-year perspective. J Athl Train. 2000;35(2):161.

11. McCarthy MM, Voos JE, Nguyen JT, Callahan L, Hannafin JA. Injury profile in elite female basketball athletes at the Women's National Basketball Association combine. Am J Sports Med. 2013;41(3):645-651.

12. Junge A, Engebretsen L, Alonso JM, et al. Injury surveillance in multisport events-the IOC approach. Br J Sports Med. 2008.

13. Kerkhoffs GM, van den Bekerom M, Elders LA, et al. Diagnosis, treatment and prevention of ankle sprains: an evidence-based clinical guideline. Br J Sports Med. 2012:bjsports-2011.

14. Hickey GJ, Fricker PA, McDonald WA. Injuries of young elite female basketball players over a six-year period. Clin J Sport Med Off J Can Acad Sport Med. 1997;7(4):252-256.

15. Parkkari J, Pasanen K, Mattila V, Kannus P, Rimpelä A. The risk for cruciate ligament injury of the knee in adolescents and young adults a population-based cohort study of 46,500 persons with 9-year follow-up. Br J Sports Med. 2008.

16. Prodromos CC, Han Y, Rogowski J, Joyce B, Shi K. A meta-analysis of the incidence of anterior cruciate ligament tears as a function of gender, sport, and a knee injury-reduction regimen. Arthrosc J Arthrosc Relat Surg. 2007;23(12):1320-1325.

17. Rochcongar P. Le genou aigu du sportif. Rev Rhum. 2006;6(73):582-587.

18. Rangger C, Kathrein A, Klestil T, Glötzer W. Partial meniscectomy and osteoarthritis. Sports Med. 1997;23(1):61-68.
19. Jarde O, Dufour O, Paclot R, Decoopman M, Vives P. Rupture du tendon d'Achille. Attitude thérapeutique à propos de 28 ruptures opérées chez le sportif. Sci Sports. 1987;2(3):177-183.

20. Le Goff P, Guillodo Y, Saraux A. La pathologie discale et la pratique sportive. Sci Sports. 1999;14(1):10-14.

21. Van der Worp H, De Poel HJ, Diercks RL, Van Den Akker-Scheek I Zwerver J. Jumper's knee or lander's knee? A systematic review of the relation between jump biomechanics and patellar tendinopathy. Int $J$ Sports Med. 2014;35(8):714-722.

22. Lian ØВ, Engebretsen L, Bahr R. Prevalence of jumper's knee among elite athletes from different sports: a cross-sectional study. Am J Sports Med. 2005;33(4):561-567.

23. Rovere GD, Clarke TJ, Yates CS, Burley K. Retrospective comparison of taping and ankle stabilizers in preventing ankle injuries. Am J Sports Med. 1988;16(3):228-233.

24. Van der Worp H, van Ark M, Roerink S, Pepping G-J, van den AkkerScheek I, Zwerver J. Risk factors for patellar tendinopathy: a systematic review of the literature. Br J Sports Med. 2011:bjsports84079.

25. Rudavsky A, Cook J. Physiotherapy management of patellar tendinopathy (jumper's knee). J Physiother. 2014;60(3):122-129.

26. Van Gent BR, Siem DD, van Middelkoop M, van Os TA, BiermaZeinstra SS, Koes BB. Incidence and determinants of lower extremity running injuries in long distance runners: a systematic review. Br J Sports Med. 2007

27. Zwerver J, Bredeweg SW, van den Akker-Scheek I. Prevalence of Jumper's knee among nonelite athletes from different sports: a crosssectional survey. Am J Sports Med. 2011;39(9):1984-1988.

28. Kettunen JA, Kvist M, Alanen E, Kujala UM. Long-Term Prognosis for Jumper's Knee in Male Athletes: Prospective Follow-up Study. Am J Sports Med. 2002;30(5):689-692.

29. Wearing SC, Smeathers JE, Urry SR, Hennig EM, Hills AP. The pathomechanics of plantar fasciitis. Sports Med. 2006;36(7):585-611.

30. Irving DB, Cook JL, Menz HB. Factors associated with chronic plantar heel pain: a systematic review. J Sci Med Sport. 2006;9(1-2):11-22.

31. Binu MG, Iesa M, Vinodini C, Nizar A. Relationship of Prevalence of Plantar Fasciitis to the Type of Flooring-A Community Based Observational Study. Indian J Public Health Res Dev. 2013;4(2).

32. Paavola M, Kannus P, Paakkala T, Pasanen M, Järvinen M. Long-term prognosis of patients with Achilles tendinopathy. Am J Sports Med. 2000;28(5):634-642.

33. Menz HB, Zammit GV, Landorf KB, Munteanu SE. Plantar calcaneal spurs in older people: longitudinal traction or vertical compression? $J$ Foot Ankle Res. 2008;1(1):7.

34. Järvinen TA, Kannus P, Maffulli N, Khan KM. Achilles tendon disorders: etiology and epidemiology. Foot Ankle Clin. 2005;10(2):255-266.

35. Vesperini V. Les tendinopathies de la cheville et du pied. Rev Rhum Monogr. 2014;81(3):153-161. 